\title{
Synthesis, Antiproliferative and Anti-inflammatory Activities of Novel Simplified Imatinib Analogues
}

Thiago Stevanatto Sampaio ${ }^{1,2}$, Lídia Moreira Lima ${ }^{1,2 *}$, Renata da Silva Zardo ${ }^{1,2}$, Cláudia Pessoa ${ }^{3}$, Bruno Coêlho Cavalcanti ${ }^{3}$, Rosane de Paula Castro $^{4}$, José Ricardo Sabino ${ }^{4}$, Patrícia Dias Fernandes ${ }^{1,2}$ and Eliezer J Barreiro ${ }^{1,2 *}$

${ }^{1}$ Instituto Nacional de Ciência e Tecnologia de Fármacos e Medicamentos, Laboratório de Avaliação e Síntese de Substâncias Bioativas, Universidade Federal do Rio de Janeiro, CCS, Cidade Universitária, Rio de Janeiro-RJ, Brazil

${ }^{2}$ Programa de Pós-Graduação em Farmacologia e Química Medicinal, Instituto de Ciências Biomédicas, Universidade Federal do Rio de Janeiro, CCS, Cidade Universitária, Rio de Janeiro-RJ, Brazil

${ }^{3}$ Laboratório Nacional de Oncologia Experimental, Departamento de Fisiologia e Farmacologia, Faculdade de Medicina, Universidade Federal do Ceará, Fortaleza-CE, Brazil

${ }^{4}$ Instituto de Física, Universidade Federal de Goiás, Goiânia-GO, Brazil

\begin{abstract}
We described the synthesis of carboxamide derivatives designed as novel simplified imatinib analogues and their antiproliferative and anti-inflammatory activities. Compound $2 \mathrm{c}$ showed a unique conformation determined by $\mathrm{X}$-ray diffraction and by NMR ${ }^{1} \mathrm{H}$ and displayed antiproliferative potency in the same magnitude order than the standard imatinib. Compounds 6-10 were prepared by structural modification in carboxamide 2c, and with exception of derivative 10 , they were inactive as antiproliferative agent. However, these compounds showed same anti-inflammatory potency than imatinib, standing out carboxamide 9 that was six time more potent as TNF- $\alpha$ inhibitor production.
\end{abstract}

Keywords: Anti-inflammatory, Antiproliferative, Carboxamide, Imatinib analogues, TNF- $\alpha$ inhibitor

\section{Introduction}

Imatinib, the first tyrosine-kinase inhibitor to be approved for the treatment of cancer, mainly chronic myelogenous leukemia (CML) and gastrointestinal stromal tumors (GISTs) [1], is considered a milestone in small-molecule drug discovery and molecular targeted therapies. However, unlike the previous report, imatinib is not a specific inhibitor of ABL, but also inhibits PDGFRs, KIT, ARG (abl-related gene) and potentially other enzymes, which have not yet been tested [2]

Besides its antineoplastic effects, anti-inflammatory and antifibrotic activity has recently been assign to imatinib, revealing its multitarget profile [3-7]. However, its exact anti-inflammatory mechanism of action remains elusive. Nonetheless, its ability to downregulate the expression of inflammatory cytokines, like TNF- $\alpha$, IL-6 and IL- $1 \beta$, has been considered a possible mechanism $[4,6]$.

In this paper we describe the synthesis, antiproliferative and anti-inflammatory activities of novel carboxamide derivatives $(2 \mathrm{a}-\mathrm{c})$ designed as simplified imatinib analogues (Figure 1) in order to obtain new anti-inflammatory drug candidates.

\section{Results and Discussion}

The carboxamide derivatives $(2 \mathrm{a}-\mathrm{c})$ were planned by molecular simplification [8] in the structure of the prototype imatinib (1), resulting in the elimination of 4-(pyridin-3-yl)pyrimidin-2-amine moiety (Subunit A, Figure 1), followed by the classic ring isosterism and retroisosterism [9] of subunits B and C, respectively (Figure 1).

The regioisomers $(2 \mathrm{a}-\mathrm{c})$ were synthesized in three linear steps depicted in Scheme 1. The synthetic route began with reductive amination step, involving the reaction of 2- or 3- or 4-nitrobenzaldehyde (3a-c) with 1-methylpiperazine in the presence of zinc chloride in methanol and sodium cyanoborohydride to obtain the nitrobenzyl$\mathrm{N}$-methyl-piperazines $4 \mathrm{a}-\mathrm{c}$ in moderate yield [10]. Interconversion of functional group was carried out based on the reduction of nitro group in respective amine derivatives $(5 a-c)$, using metallic iron in the presence of slightly acid solution of ammonium chloride in water and ethanol (1:1) [11]. The condensation of the amines 5a-c with 2-quinaxaloyl chloride, at room temperature using dichloromethane

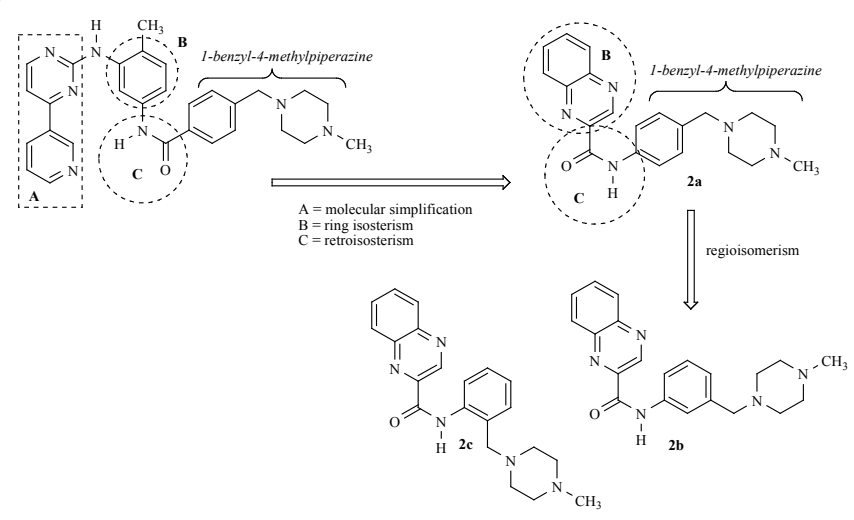

Figure 1: Design conception of carboxamide derivatives (2a-c) through molecular simplification from imatinib.

as solvent [12], obtained the desired carboxamides $2 \mathrm{a}-\mathrm{c}$ in good yields (Scheme 1). The regioisomers $2 \mathrm{a}-\mathrm{c}$ were fully characterized by ${ }^{1} \mathrm{H}$ $\mathrm{NMR},{ }^{13} \mathrm{C}$ NMR and IR spectroscopy and their purity was determined by elementar analysis or HPLC. The possible conformation differences, arising from the isomerism in the benzyl- $N$-methylpiperazine unit, were assigned based on the X-ray crystallographic studies performed with carboxamides 2a-c (Figure 2 and Table 1).

*Corresponding authors: LM Lima, Laboratório de Avaliação e Síntese de Substâncias Bioativas, Universidade Federal do Rio de Janeiro, P.O. Box 68024, Zip code: 21944-971, Rio de Janeiro, RJ, Brazil, Tel.+55(21)39386503; E-mail: lidia@lassbio.icb.ufrj.br

EJ Barreiro, Laboratório de Avaliação e Síntese de Substâncias Bioativas, Universidade Federal do Rio de Janeiro, P.O. Box 68024, Zip code: 21944-971. Rio de Janeiro, RJ, Brazil, Tel.: +55(21)39386644; Fax: +55(21)39386478; E-mail: ejbarreiro@ccsdecania.ufr.br

Received November 05, 2014; Accepted November 21, 2014; Published November 23, 2014

Citation: Sampaio TS, Lima LM, da Silva Zardo R, Pessoa C, Cavalcanti BC et al. (2014) Synthesis, Antiproliferative and Anti-inflammatory Activities of Novel Simplified Imatinib Analogues. Med chem 4: 756-762. doi:10.4172/21610444.1000226

Copyright: ( 2014 Sampaio TS, et al. This is an open-access article distributed under the terms of the Creative Commons Attribution License, which permits unrestricted use, distribution, and reproduction in any medium, provided the original author and source are credited. 


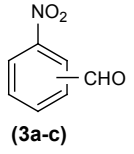

(a) = para, (b) $=$ meta
(c) $=$ orth

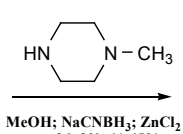

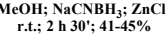
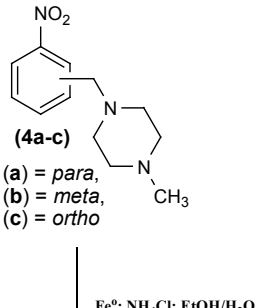
reflux; $; 1$ h; $74-83 \%$
int<smiles>O=C(Cl)c1cnc2ccccc2n1</smiles>
$\mathrm{Et}_{3} \mathrm{~N} ; \mathrm{CH}_{2} \mathrm{Cl}_{2} ;$
r.t.; 2 h; $51-64 \%$

(2a-c)

(a) $=$ para,
(b) $=$ meta

(c) $=$ ortho

Scheme 1: Synthesis of compounds 2a-c.

A
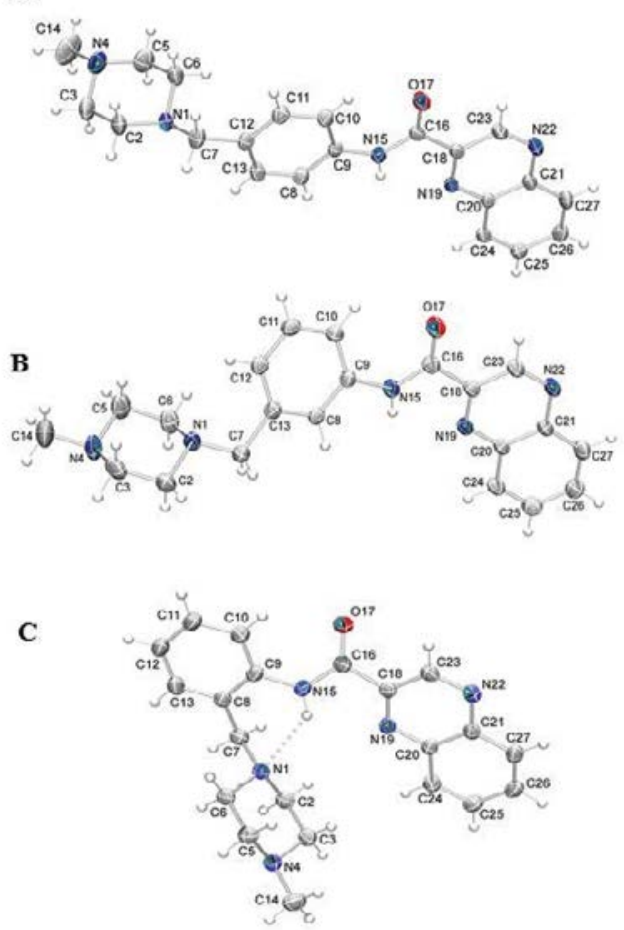

Figure 2: ORTEP view of compounds 2a-c with the atom displacement ellipsoids drawn at $30 \%$ of probability level. A) compound $2 \mathrm{a}$; B) compound $2 \mathrm{~b}$; C) compound $2 \mathrm{c}$.

Single crystals of compounds $2 \mathrm{a}-\mathrm{c}$ were obtained and subjected to X-ray diffraction; the ORTEP [13] view is shown in Figure 2a-2c. The different positioning of the piperazine moiety leads to changes in the carboxamide fragment conformation in solid state. These changes occur in the angles between the planes passing through the atoms of the planar subunits quinoxaline C18/N19/C20/C24/C25/ C26/C27/ C21/N22/C23 (plane $\alpha$ ), the acetamide bridge N15/C16/C18/O17 (plane $\beta$ ) and the phenyl ring $\mathrm{C} 8 / \mathrm{C} 9 / \mathrm{C} 10 / \mathrm{C} 11 / \mathrm{C} 12 / \mathrm{C} 13$ (plane $\gamma$ ). The piperazine conformation relative to the phenyl ring is also subject to torsional strain about the $\sigma$-bonding between $\mathrm{N} 1$ atom and the methylene carbon C7, where the methylene's hydrogen is eclipsed in $2 \mathrm{a}$ and $2 \mathrm{c}$ and staggered in $2 \mathrm{~b}$. Bond lengths are in good agreement between the three compounds. It is worth to notice that the density increases from compound $2 \mathrm{a}$ to $2 \mathrm{c}$, showing that in compound $2 \mathrm{c}$, the intramolecular N15-H15...N1 H-bond leads to a more compact molecular conformation when compared to $2 \mathrm{a}$ and $2 \mathrm{~b}$.

In order to establish the better regioisomer template to be elected as a new lead compound, with an original structural pattern, the antiproliferative activity of carboxamides $2 \mathrm{a}-\mathrm{c}$ was investigated against HL-60 (human leukemia), SF-295 (human glioblastoma) and HCT8 (human colorectal carcinoma) tumor cell lines [14]. In this assay, doxorubicin was used as positive control and imatinib as standard drug. As demonstrated in Table 2, the regioisomer para (2a) and meta (2b) were inactive, while the regioisomer ortho (2c) displayed antiproliferative potency similar to the prototype imatinib, against human colorectal carcinoma and human leukemia cells. In addition, compound $2 \mathrm{c}$ was not cytotoxic against healthy cells (i.e. human lymphocyte).

The differences in the antiproliferative activity of carboxamides $2 \mathrm{a}$ c, especially the ortho regioisomer (2c), can be attributed to its unique conformation due to the presence of intramolecular hydrogen bond (N1 and H15) observed in the solid state, by X-ray diffraction (Figure $2 \mathrm{C}$ and Table 1), and confirmed in solution by ${ }^{1} \mathrm{H}$ NMR, through the differences in the chemical shift of the amide hydrogen (CONH $)$ of compounds $2 \mathrm{a}-\mathrm{c}$. The $\mathrm{NH}$ proton signal for compounds $2 \mathrm{a}$ and $2 \mathrm{~b}$ is seen at 9.75 and $9.79 \mathrm{ppm}$, while for compound $2 \mathrm{c}$ signal moves downfield to $\delta 11.7 \mathrm{ppm}$, due a deshielding effect promoted by the intramolecular

\begin{tabular}{|c|c|c|c|c|c|}
\hline Compound & D-H...A & $\mathrm{D}-\mathrm{H}$ & H...A & D...A & D-H...A \\
\hline \multicolumn{6}{|c|}{ Intermolecular } \\
\hline $2 a$ & $\mathrm{C} 10-\mathrm{H} 10 \ldots \mathrm{O} 17^{\mathrm{iii}}$ & 0.93 & 2.33 & $3.259(2)$ & 124 \\
\hline $2 b$ & $\mathrm{~N} 15-\mathrm{H} 15 \ldots \mathrm{N} 22^{\mathrm{iv}}$ & 0.93 & 2.33 & $3.259(2)$ & 124 \\
\hline 2c & $\mathrm{C} 3-\mathrm{H} 3 \mathrm{~b} \ldots \mathrm{O} 17^{v}$ & 0.97 & 2.52 & $3.270(2)$ & 135 \\
\hline 2c & $\mathrm{C} 7-\mathrm{H} 7 \mathrm{a} \ldots \mathrm{Cg} 1^{\text {vii }}$ & 0.97 & 2.45 & $3.367(2)$ & 157 \\
\hline \multicolumn{6}{|c|}{ Intramolecular } \\
\hline 2c & N15-H15...N1 & 0.86 & 2.24 & $2.915(2)$ & 136 \\
\hline
\end{tabular}

Table 1: Hydrogen-bonds and intermolecular interactions geometry $\left(\AA,{ }^{\circ}\right)$.

\begin{tabular}{|c|c|c|c|c|}
\hline Compound & \multicolumn{2}{|c|}{ Cell Lines - IC $_{\mathbf{5 0}} \boldsymbol{\mu M} \pm$ S.E.M } & $\begin{array}{c}\text { Primary } \\
\text { culture }\end{array}$ \\
\hline & HL-60 & SF-295 & HCT-8 & $\begin{array}{c}\text { Human } \\
\text { Lymphocytes }\end{array}$ \\
\hline 2a (LASSBio-1599) & $>300$ & $208.67 \pm 7.28$ & $\begin{array}{c}173.41 \pm \\
5.91\end{array}$ & $194.3 \pm 2.17$ \\
\hline 2b (LASSBio-1598) & $>300$ & $287.53 \pm 3.15$ & $>300$ & $>300$ \\
\hline 2c (LASSBio-1597) & $74.40 \pm 9.80$ & $107.64 \pm 5.10$ & $\begin{array}{c}39.61 \pm \\
7.05\end{array}$ & $>300$ \\
\hline $\mathbf{6}$ (LASSBio-1724) & $>300$ & $>300$ & $>300$ & $>300$ \\
\hline $\mathbf{7}$ (LASSBio-1725) & $>300$ & $>300$ & $>300$ & $>300$ \\
\hline $\mathbf{8}$ (LASSBio-1726) & $>300$ & $>300$ & $>300$ & $>300$ \\
\hline $\mathbf{9}$ (LASSBio-1723) & $>300$ & $>300$ & $>300$ & $>300$ \\
\hline $\mathbf{1 0}$ (LASSBio-1727) & $35.75 \pm 2.51$ & $>300$ & $>300$ & $>300$ \\
\hline Imatinib & $22.81 \pm 3.11$ & $41.53 \pm 5.73$ & $34.03 \pm$ & $>300$ \\
\hline Doxorubicin & $0.04 \pm 0.01$ & $0.48 \pm 0.02$ & $0.02 \pm 0.01$ & $0.37 \pm 0.01$ \\
\hline
\end{tabular}

HL-60 (human leukemia); SF-295 (human glioblastoma); HCT-8 (human colorectal carcinoma)

Table 2: Antiproliferative activity of carboxamides 2a-c, imatinib and doxorubicin (positive control) against HL-60, SF-295, HCT-8 tumor cell lines and their cytotoxic activity against primary culture of human lymphocytes. 
hydrogen bond between $\mathrm{H} 15(\mathrm{XON} \underline{\mathrm{H}})$ and $\mathrm{N} 1$ (piperazine), defining a six-membered ring (Figure 2C).

Once defined the ortho scaffold as the better template to achieve new imatinib analogues, the carboxamide $2 \mathrm{c}$ was modified varying the nature of the $N$-substituted piperazine (8-10) and by bioisosteric replacement [9] of the quinoxaline ring (6-7) (Figure 3). These analogues were synthesized applying the same methodology previously described for carboxamides $2 \mathrm{a}-\mathrm{c}$, exploring steps of reductive amination, functional group interconversion and condensation of amines with acyl chlorides derivatives (Scheme 2).

The analogues 6-10 were also evaluated as antiproliferative leadcandidates (Table 2). As show in Table 2 the attempt to replace the quinoxaline ring (2c) by the pyrazine system (6) or by the retroisoster 7 resulted in loss of activity. Also, the substitution of methyl group linked in the piperazine subunit by an aromatic group (phenyl or pyrimidine) resulted in failure of antiproliferative activity. However, compound
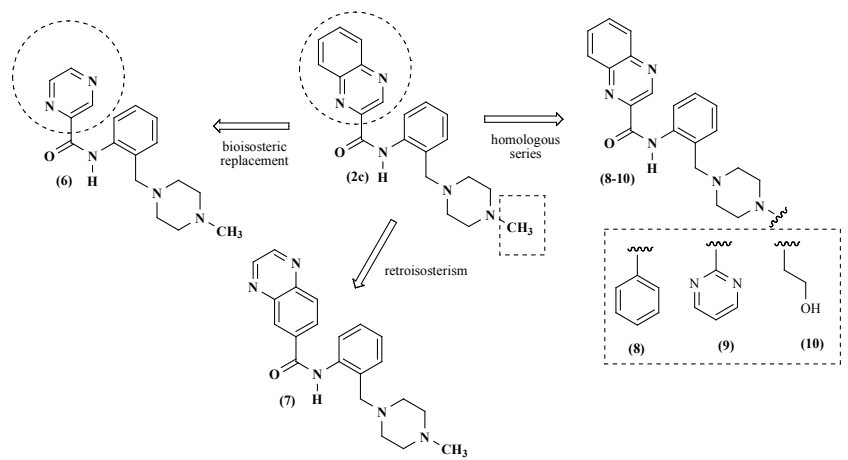

Figure 3: Design conception of carboxamide derivatives (6-10) from the prototype 2c.

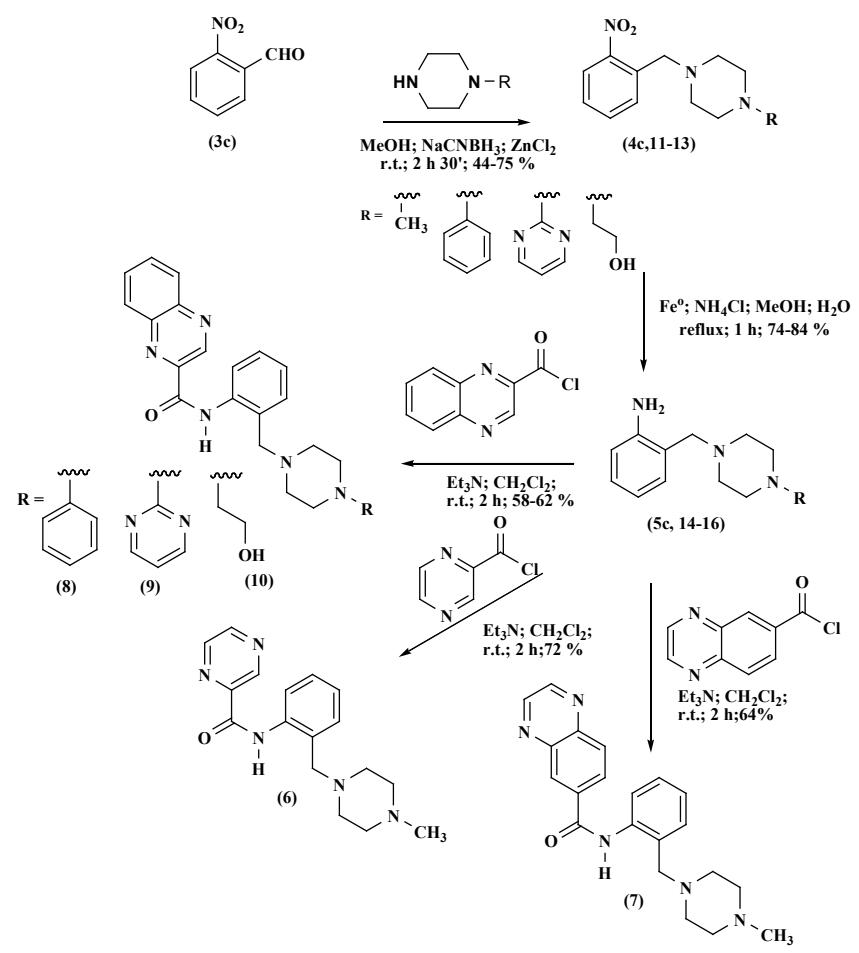

Scheme 2: Synthesis of compounds 6-10
10, having a 1-(2-hydroxyethyl) piperazine unit, instead of the $\mathrm{N}$-methylpiperazine presented in the lead $2 \mathrm{c}$, seems to present a more selective cytotoxic profile, being active against human leukemia (HL60) and inactive against the solid tumor cells lines SF-295 and HCT-8.

Considering the recent anti-inflammatory profile described for the prototype imatinib, the carboxamides $2 \mathrm{c}$ and 6-10 were studied in carrageenan-induced acute inflammation in the mouse air pouch synovial model [15]. In this model, the number of leukocytes recruited into the pouch increased progressively after carrageenan, and the ability of carboxamides derivatives and the prototype imatinib to inhibit the cell migration and to reduce the cytokine TNF- $\alpha$ production were investigated. As shown in Table 3, imatinib (1) and carboxamides $2 \mathrm{c}$ and 6-10, when administered per os, were able to inhibit the leukocyte migration revealing an important anti-inflammatory profile with $\mathrm{ED}_{50}$ (in $\mu \mathrm{mol} / \mathrm{kg}$ ) values similar to imatinib. In order to verify the anti-TNFactivity of these derivatives, we quantified the TNF- $\alpha$ produced in the SAP exsudate. As shown in Table 3, compound 9 standing out, showing $\mathrm{ED}_{50}$ value of $0.07 \mu \mathrm{mol} / \mathrm{kg}$, being more potent than imatinib $\left(\mathrm{ED}_{50}\right.$ value of $0.44 \mu \mathrm{mol} / \mathrm{kg}$ ).

\section{Conclusion}

In summary, similar to imatinib (1) and the initial prototype $2 c$, all carboxamide derivatives described herein (6-10) showed an important anti-inflammatory and anti-TNF- $\alpha$ activity in vivo. Compound 9, having a pyrimidine group linked to piperazine ring was six times more potent as TNF- $\alpha$ production inhibitor than imatinib (1). It is noteworthy that modifications introduced in quinoxaline ring or piperazine unit were able to dissociate the anti-inflammatory effect in the detriment of the antiproliferative activity, as exemplified by compounds 6-9. From this series of simplified imatinib analogues, only compounds $2 \mathrm{c}$ and 10 showed both cytotoxic and anti-inflammatory activities.

\section{Experimental Section}

\section{Chemistry}

All commercially available reagents and solvents were used without further purification. Reactions were routinely monitored by thinlayer chromatography (TLC) in silica gel (F245 Merck plates) and the products visualized with ultraviolet lamp $(254$ and $365 \mathrm{~nm}) .{ }^{1} \mathrm{H}$ and ${ }^{13} \mathrm{C}$ nuclear magnetic resonance (NMR) spectra were determined in $\mathrm{CDCl}_{3}$ solution using a Bruker AC-200. The chemical shifts are given in parts per million $(\delta)$ from solvent residual peaks and the coupling constant values $(J)$ are given in Hz. Signal multiplicities are represented by: s, singlet; d, doublet; m, multiplet; Is, large signal. Infrared (IR) spectra were obtained with ABB spectrophotometer, FTLA 2000-100

\begin{tabular}{|c|c|c|}
\hline Compound & $\mathrm{ED}_{50}(\mu$ & $\mathrm{l} / \mathbf{k g})$ \\
\hline & Leukocyte migration & TNF- $\alpha$ production \\
\hline ASA & $128.0^{*}$ & N.R. \\
\hline imatinib & $5.0^{*}$ & $0.44^{*}$ \\
\hline 2c (LASSBio-1597) & $5.1^{*}$ & $4.4^{*}$ \\
\hline 6 (LASSBio-1724) & $5.35^{*}$ & $9.26^{*}$ \\
\hline 7 (LASSBio-1725) & $6.1^{*}$ & $8.8^{*}$ \\
\hline 8 (LASSBio-1726) & $3.2^{*}$ & $8.6^{*}$ \\
\hline 9 (LASSBio-1723) & $4.45^{*}$ & $0.07^{*}$ \\
\hline 10 (LASSBio-1727) & $5.4^{*}$ & $0.9^{*}$ \\
\hline
\end{tabular}

-N.R. not realized; ASA = acetylsalicylic acid. $\mathrm{N}=7-10$ per group. Doses: $1-50$ $(\mu \mathrm{mol} / \mathrm{kg})$. Statistical significance between groups was calculated using analysis of variance (ANOVA) followed by Bonferroni test. $P$ values less than $0.05\left({ }^{*} p<0.05\right)$ were used as significant level.

Table 3: Effects of carboxamides 2c, 6-10, imatinib and acetylsalicylic acid (ASA) in leukocyte migration and TNF- $\alpha$ production induced by carrageenan injection into the subcutaneous air pouch. 
model, by using potassium bromide plates. Elemental analysis results were obtained with a Thermo CE scientific apparatus, EA 1112 Series model. Melting points were determined using a Quimis Melting Point Q-340S13 and are uncorrected. Flash chromatography was performed using a LaFlash system (VWR) with Merck silica gel $(25-40 \mu \mathrm{m})$.

The TLC was performed on $2.0 \times 6.0 \mathrm{~cm}$ aluminium sheets covered with silica gel (Sorbent, $200 \mu \mathrm{m}$ thickness) under ultraviolet light (254$365 \mathrm{~nm})$.

The high performance liquid chromatography was performed using Shimadzu - LC20AD with Kromasil column 100-5C18 (4,6 mm $\times 250$ $\mathrm{mm}$ ), SPD-M20A detector (Diode array) at a wavelength of $254 \mathrm{~nm}$. The mobile phases used: $30 \%$ acetonitrile and $70 \%$ aqueous trifluoroacetic acid $0,01 \%$ or $50 \%$ acetonitrile and $50 \%$ aqueous trifluoroacetic acid $0,01 \%$

Analyses by differential scanning calorimetry were obtained with DSC-60 Shimadzu. The samples were heated at a rate of $20^{\circ} \mathrm{C} / \mathrm{min}$, with a temperature range of $30-300^{\circ} \mathrm{C}$ under a nitrogen flow.

General procedure for the preparation of compounds 4a-c, 11-13 [10]: To a $100 \mathrm{~mL}$ flask $6.6 \mathrm{mmol}$ of nitrobenzaldehyde was dissolved in methanol $(15 \mathrm{~mL})$. Then, $26.4 \mathrm{mmol}$ of 1-methylpiperazine were added. After 30 minutes, 6.6 moles of sodium cyanoborohydride and $3.3 \mathrm{~mol}$ of zinc chloride, previously dissolved in $10 \mathrm{~mL}$ of methanol, were added. The mixture was stirred for 2 hours. The end of this step was observed by TLC and desired product was extracted using $20 \mathrm{~mL}$ of $\mathrm{NaOH} 0.1 \mathrm{~N}$ and $3 \times 30 \mathrm{~mL}$ of ethyl acetate. Afterwards, organic phases was put together, dried and solvent was evaporated under reduced. The products were purified by column chromatography on silica gel (eluent n-hexane:Ethyl Acetate 50:50).

1-(4-nitrobenzyl)-4-methylpiperazine (4a): Yield: orange oil (41\%); ${ }^{1} \mathrm{H}$ NMR $\left(200 \mathrm{MHz}, \mathrm{CDCl}_{3}\right) \delta 2.26\left(\mathrm{~s}, 3 \mathrm{H}, \mathrm{CH}_{3}\right), 2.45(\mathrm{ls}, 8 \mathrm{H}$, $\mathrm{Ha}$ and $\mathrm{Hb}), 3.56\left(\mathrm{~s}, 2 \mathrm{H}, \mathrm{CH}_{2}\right), 7.47\left(\mathrm{~d}, 2 \mathrm{H}, J=8.5 \mathrm{~Hz}, \mathrm{H} 3{ }^{\prime}\right.$ and $\left.\mathrm{H} 5^{\prime}\right)$, $8.12\left(\mathrm{~d}, 2 \mathrm{H}, J=8.5 \mathrm{~Hz}, \mathrm{H} 4\right.$ ' and $\left.\mathrm{H} 6{ }^{\prime}\right) ;{ }^{13} \mathrm{C} \mathrm{NMR}\left(50 \mathrm{MHz}, \mathrm{CDCl}_{3}\right) \delta 46.1$ (Cc), 53.2 (Ca and $\left.\mathrm{Ca}^{\prime}\right), 55.1\left(\mathrm{Cb}\right.$ and $\left.\mathrm{Cb}^{\prime}\right), 62.2(\mathrm{Cd}), 123.6(\mathrm{C}-2$ and C-2'), 129.6 (C-3 and C-3'), 146.5 (C-4), 147.3 (C-1); IR (KBr) 3050 $\mathrm{cm}^{-1}$ (v C-H aromatics), 2937 and $2793 \mathrm{~cm}^{-1}\left(v \mathrm{CH}_{2}\right), 1514 \mathrm{~cm}^{-1}\left(v_{\mathrm{a}}\right.$ $\left.\mathrm{NO}_{2}\right), 1342 \mathrm{~cm}^{-1}\left(v_{\mathrm{s}} \mathrm{NO}_{2}\right), 855 \mathrm{~cm}^{-1}\left(\delta_{\text {out of the plane }} \mathrm{C}-\mathrm{H}\right.$ of aromatic ring para-substituted).

1-(3-nitrobenzyl)-4-methylpiperazine (4b): Yield: orange oil (45\%); ${ }^{1} \mathrm{H}$ NMR $\left(200 \mathrm{MHz}, \mathrm{CDCl}_{3}\right) \delta 2.30\left(\mathrm{~s}, 3 \mathrm{H}, \mathrm{CH}_{3}\right), 2.48(\mathrm{ls}, 8 \mathrm{H}, \mathrm{Ha}$ and $\mathrm{Hb}), 3.60\left(\mathrm{~s}, 2 \mathrm{H}, \mathrm{CH}_{2}\right), 7.48\left(\mathrm{t}, 1 \mathrm{H}, J=7.8 \mathrm{~Hz}, \mathrm{H} 5^{\prime}\right), 7.68(\mathrm{~d}, 1 \mathrm{H}, J=$ $\left.7.5 \mathrm{~Hz}, \mathrm{H} 4^{\prime}\right), 8.10\left(\mathrm{~d}, 1 \mathrm{H}, J=8.1 \mathrm{~Hz}, \mathrm{H}^{\prime}\right), 8.21\left(\mathrm{~s}, 1 \mathrm{H}, \mathrm{H} 2^{\prime}\right) ;{ }^{13} \mathrm{C} \mathrm{NMR}$ $\left(50 \mathrm{MHz}, \mathrm{CDCl}_{3}\right) \delta 46.0(\mathrm{Cc}), 53.1$ (Ca and $\left.\mathrm{Ca}^{\prime}\right), 55.1\left(\mathrm{Cb}\right.$ and $\left.\mathrm{Cb}^{\prime}\right), 62.0$ (Cd), 122.2 (C-6), 123.7 (C-2), 129.1 (C-5), 135.0 (C-4), 140.9 (C-3), 148.5 (C-1); IR (KBr) $3045 \mathrm{~cm}^{-1}$ (v C-H aromatic), $1527 \mathrm{~cm}^{-1}\left(v_{\mathrm{a}} \mathrm{NO}_{2}\right)$, $1318 \mathrm{~cm}^{-1}\left(v_{\mathrm{s}} \mathrm{NO}_{2}\right), 751$ and $689 \mathrm{~cm}^{-1}\left(\delta_{\text {out of the plane }} \mathrm{C}-\mathrm{H}\right.$ of aromatic rings meta-substituted).

1-(2-nitrobenzyl)-4-methylpiperazine (4c): Yield: yellow solid (44\%); MP: $170-171^{\circ} \mathrm{C}$; ${ }^{1} \mathrm{H}$ NMR $\left(200 \mathrm{MHz}, \mathrm{CDCl}_{3}\right) \delta 2.25$ (s, 3H, $\left.\mathrm{CH}_{3}\right), 2.44(\mathrm{ls}, 8 \mathrm{H}, \mathrm{Ha}$ and $\mathrm{Hb}), 3.53\left(\mathrm{~s}, 2 \mathrm{H}, \mathrm{CH}_{2}\right), 7.41(\mathrm{t}, 1 \mathrm{H}, J=7.5$ $\mathrm{Hz}, \mathrm{H} 4$ '), 7.60 (d, $1 \mathrm{H}, J=7.6 \mathrm{~Hz}, \mathrm{H} 3$ '), 8.03 (m, 1H, H5'), 8.14 (ls, $1 \mathrm{H}$, $\mathrm{H} 6$ ) ; ${ }^{13} \mathrm{C}$ NMR (50 MHz, $\mathrm{CDCl}_{3}$ ) $\delta 46.0$ (Cc), 53.0 (Ca and Ca'), 55.1 (Cb and $\left.\mathrm{Cb}^{\prime}\right), 62.0$ (Cd), 122.3 (C-2), 123.8 (C-6), 129.3 (C-5), 135.1 (C-4), 140.9 (C-3), 148.5 (C-1); IR (KBr) 2938 and $2797 \mathrm{~cm}^{-1}\left(\mathrm{v} \mathrm{CH}_{2}\right)$, $1528 \mathrm{~cm}^{-1}\left(v_{\mathrm{a}} \mathrm{NO}_{2}\right), 1356 \mathrm{~cm}^{-1}\left(\mathrm{v}_{\mathrm{s}} \mathrm{NO}_{2}\right)$.

1-(2-nitrobenzyl)-4-phenylpiperazine (11): Yield: yellow solid (71\%); MP: $108-109{ }^{\circ} \mathrm{C} ;{ }^{1} \mathrm{H}$ NMR $\left(200 \mathrm{MHz}, \mathrm{CDCl}_{3}\right) \delta 2.52$ (t, 4H, $J=$ $4.9 \mathrm{~Hz}, \mathrm{Ha}), 3.08(\mathrm{t}, 4 \mathrm{H}, J=4.9 \mathrm{~Hz}, \mathrm{Hb}), 3.78\left(\mathrm{~s}, 2 \mathrm{H}, \mathrm{CH}_{3}\right), 6.77(\mathrm{~m}, 3 \mathrm{H}$, H3", H4" and H5"), 7.16 (m, 2H, H2" and H6"), 7.31 (m, 1H, , H5'), $7.46\left(\mathrm{~m}, 1 \mathrm{H}, \mathrm{H} 4^{\prime}\right), 7.57\left(\mathrm{~d}, 1 \mathrm{H}, J=6.9 \mathrm{~Hz}, \mathrm{H3}{ }^{\prime}\right), 7.74(\mathrm{~d}, 1 \mathrm{H}, J=7.9 \mathrm{~Hz}$ $\mathrm{H} 6$ '); ${ }^{13} \mathrm{C} \mathrm{NMR}\left(50 \mathrm{MHz}, \mathrm{CDCl}_{3}\right) \delta 49.2$ ( $\mathrm{Cb}$ and $\left.\mathrm{Cb}^{\prime}\right), 53.2$ (Ca and $\left.\mathrm{Ca}^{\prime}\right)$, $59.0(\mathrm{Cc}), 116.2$ (C-2' and C-6'), 119.8 (C-2), 124. 5 (C-4'), 128.1 (C-6), 129.1 (C-3' and C-5'), 131.1 (C-5), 132.5 (C-4), 133.5 (C-3), 150.0 (C1), 151.3 (C-1'); IR (KBr) 2952 and $2817 \mathrm{~cm}^{-1}\left(\mathrm{v} \mathrm{CH}_{2}\right), 1596,1492$ and $1443 \mathrm{~cm}^{-1}$ (v C=C aromatic), $1525 \mathrm{~cm}^{-1}\left(v_{\mathrm{a}} \mathrm{NO}_{2}\right), 1348 \mathrm{~cm}^{-1}\left(\mathrm{v}_{\mathrm{s}} \mathrm{NO}_{2}\right)$.

1-(2-nitrobenzyl)-4-(2-pyrimidyl)piperazine (12): Yield: white solid (71\%); MP: 110-112 ${ }^{\circ} \mathrm{C}$; ${ }^{1} \mathrm{H}$ NMR (200 MHz, $\left.\mathrm{CDCl}_{3}\right) \delta 2.37(\mathrm{t}$, $4 \mathrm{H}, J=4.6 \mathrm{~Hz}, \mathrm{Ha}), 3.65(\mathrm{t}, 4 \mathrm{H}, J=4.5 \mathrm{~Hz}, \mathrm{Hb}), 3.75\left(\mathrm{~s}, 2 \mathrm{H}, \mathrm{CH}_{2}\right)$, $6.60\left(\mathrm{t}, 1 \mathrm{H}, J=4.6 \mathrm{~Hz}, \mathrm{H} 4{ }^{\prime \prime}\right), 7.48-7.56\left(\mathrm{~m}, 1 \mathrm{H}, \mathrm{H} 3^{\prime}\right.$ and $\left.\mathrm{H} 5^{\prime}\right), 7.65$ (m, 2H, H4'), 7.87 (d, 1H, J = 7.8 Hz, H6'), 8.32 (m, 2H, H3" and H5"); ${ }^{13} \mathrm{C} \mathrm{NMR}\left(50 \mathrm{MHz}, \mathrm{CDCl}_{3}\right) \delta 43.8\left(\mathrm{Cb}\right.$ and $\left.\mathrm{Cb}^{\prime}\right), 53.0\left(\mathrm{Ca}\right.$ and $\left.\mathrm{Ca}^{\prime}\right)$, 58.7 (Cc), 110.7 - 161.6 (C-aromatics); IV (KBr) 2936 and $2821 \mathrm{~cm}^{-1}(\mathrm{v}$ $\left.\mathrm{CH}_{2}\right), 1587,1498$ and $1446 \mathrm{~cm}^{-1}$ (v C=C aromatic), $1541 \mathrm{~cm}^{-1}\left(\mathrm{v}_{\mathrm{a}} \mathrm{NO}_{2}\right)$, $1355 \mathrm{~cm}^{-1}\left(\mathrm{v}_{\mathrm{s}} \mathrm{NO}_{2}\right)$.

1-(2-nitrobenzyl)-4-(2-hydroxyethyl)piperazine (13): Yield: yellow oil (47\%); ${ }^{1} \mathrm{H}$ NMR $\left(200 \mathrm{MHz}, \mathrm{CDCl}_{3}\right) \delta 2.43-2.50(\mathrm{~m}, 8 \mathrm{H}$, $\mathrm{Ha}$ and $\mathrm{Hb}), 2.74(\mathrm{ls}, 2 \mathrm{H}, \mathrm{Hd}), 3.54(\mathrm{t}, 2 \mathrm{H}, J=5.3 \mathrm{~Hz}, \mathrm{He}), 3.73(\mathrm{~s}, 2 \mathrm{H}$, $\left.\mathrm{CH}_{2}\right), 7.28-7.36\left(\mathrm{~m}, 1 \mathrm{H}, \mathrm{H} 4{ }^{\prime}\right), 7.42-7.52\left(\mathrm{~m}, 2 \mathrm{H}, \mathrm{H} 3^{\prime}\right.$ and $\left.\mathrm{H} 5{ }^{\prime}\right), 7.73$ $\left(\mathrm{d}, 1 \mathrm{H}, J=7.7 \mathrm{~Hz}, \mathrm{H6}{ }^{\prime}\right) ;{ }^{13} \mathrm{C}$ NMR $\left(50 \mathrm{MHz}, \mathrm{CDCl}_{3}\right) \delta 53.0\left(\mathrm{Ca}\right.$ and $\left.\mathrm{Ca}^{\prime}\right)$, $53.1\left(\mathrm{Cb}\right.$ and $\left.\mathrm{Cb}^{\prime}\right), 57.8(\mathrm{Cc}), 59.1(\mathrm{Cd}), 59.4(\mathrm{Ce}), 124.5(\mathrm{C}-2), 128.1$ (C-6), 131.1 (C-5), 132.4 (C-4), 133.8 (C-3), 150.0 (C-1); IV (KBr) 3390 $\mathrm{cm}^{-1}\left(v_{\mathrm{a}} \mathrm{OH}\right), 2940$ and $2816 \mathrm{~cm}^{-1}\left(\mathrm{v} \mathrm{CH}_{2}\right), 1529 \mathrm{~cm}^{-1}\left(v_{\mathrm{a}} \mathrm{NO}_{2}\right), 1356$ $\mathrm{cm}^{-1}\left(\mathrm{v}_{\mathrm{s}}^{\mathrm{a}} \mathrm{NO}_{2}\right)$.

General procedure for preparation of intermediates 5a-c, 14-16 [11]: To a $125 \mathrm{~mL}$ flask containing $1.3 \mathrm{mmol}$ of nitro-compound and 90 $\mathrm{mL}$ of ethanol:water (2:1) were added $7.3 \mathrm{mmol}$ of iron powder and 2.1 mmol of ammonium chloride. The mixture was refluxed for 1 hour. The hot mixture was filtered through Celite and concentrated in vacuo. The residue was diluted with $\mathrm{H}_{2} \mathrm{O}$ and extracted with AcOEt. Afterwards, organic phases was dried over anhydrous $\mathrm{Na}_{2} \mathrm{SO}_{4}$ and concentrated to give the amine intermediates.

4-[(4-methylpiperazin-1-yl)methyl]benzenamine (5a): Yield: yellow solid (83\%); MP: $68-70{ }^{\circ} \mathrm{C} ;{ }^{1} \mathrm{H}$ NMR $\left(200 \mathrm{MHz}, \mathrm{CDCl}_{3}\right) \delta 2.27$ (s, $\left.3 \mathrm{H}, \mathrm{CH}_{3}\right), 2.44(\mathrm{ls}, 8 \mathrm{H}, \mathrm{Ha}$ and $\mathrm{Hb}), 3.39\left(\mathrm{~s}, 2 \mathrm{H}, \mathrm{CH}_{2}\right), 3.51(\mathrm{~s}, 2 \mathrm{H}$, $\left.\mathrm{NH}_{2}\right), 6.62\left(\mathrm{~d}, 2 \mathrm{H}, J=7.9 \mathrm{~Hz}, \mathrm{H} 3^{\prime}\right.$ and $\left.\mathrm{H} 4{ }^{\prime}\right), 7.08(\mathrm{~d}, 2 \mathrm{H}, J=7.8 \mathrm{~Hz}$, $\mathrm{H} 2$ ' and $\left.\mathrm{H}^{\prime}\right) ;{ }^{13} \mathrm{C}$ NMR $\left(50 \mathrm{MHz}, \mathrm{CDCl}_{3}\right) \delta 46.1(\mathrm{Cc}), 53.0(\mathrm{Ca}$ and Ca'), 55.2 (Cb and Cb'), 62.7 (Cd), 114.9 (C-2 and C-2'), 129.0 (C-4), 130.4 (C-3 and C-3'), 145.5 (C-1); IV (KBr) $3444 \mathrm{~cm}^{-1}\left(v_{2} \mathrm{NH}_{2}\right), 3361$ $\mathrm{cm}^{-1}\left(v_{\mathrm{s}} \mathrm{NH}_{2}\right), 2933$ and $2807 \mathrm{~cm}^{-1}\left(\mathrm{v} \mathrm{CH}_{2}\right), 1621,1518$ and $1450 \mathrm{~cm}^{-1}$ (v $\mathrm{C}=\mathrm{C}$ aromatic), $826 \mathrm{~cm}^{-1}\left(\delta_{\text {out of the plane }} \mathrm{C}-\mathrm{H}\right.$ of aromatic rings parasubstituted).

3-[(4-methylpiperazin-1-yl)methyl]benzenamine (5b): Yield: yellow solid (78\%); MP: $70-71{ }^{\circ} \mathrm{C} ;{ }^{1} \mathrm{H}$ NMR $\left(200 \mathrm{MHz}, \mathrm{CDCl}_{3}\right) \delta 2.20$ $\left(\mathrm{s}, 3 \mathrm{H}, \mathrm{CH}_{3}\right), 2.38(\mathrm{ls}, 8 \mathrm{H}, \mathrm{Ha}$ and $\mathrm{Hb}), 3.33\left(\mathrm{~s}, 2 \mathrm{H}, \mathrm{CH}_{2}\right), 3.53(\mathrm{~m}, 2 \mathrm{H}$, $\left.\mathrm{NH}_{2}\right), 6.47\left(\mathrm{~m}, 1 \mathrm{H}, \mathrm{H} 2^{\prime}\right), 6.61\left(\mathrm{~d}, 2 \mathrm{H}, J=7.0 \mathrm{~Hz}, \mathrm{H} 4^{\prime}\right.$ and $\left.\mathrm{H} 6^{\prime}\right), 7.00(\mathrm{t}$, $1 \mathrm{H}, J=7.7 \mathrm{~Hz}, \mathrm{H} 5$ ) $;{ }^{13} \mathrm{C} \mathrm{NMR}\left(50 \mathrm{MHz}, \mathrm{CDCl}_{3}\right) 46.1(\mathrm{Cc}), 53.2(\mathrm{Ca}$ and Ca'), 55.2 (Cb and Cb'), $63.1(\mathrm{Cd}), 113.9$ (C-6), 115.8 (C-2), 119.5 (C4), 129.1 (C-5), 139.5 (C-3), 146.5 (C-1); IV (KBr) $3408 \mathrm{~cm}^{-1}\left(v_{\mathrm{a}} \mathrm{NH}_{2}\right)$, $3307 \mathrm{~cm}^{-1}\left(v_{s} \mathrm{NH}_{2}\right), 2946$ and $2794 \mathrm{~cm}^{-1}\left(\mathrm{v} \mathrm{CH}_{2}\right), 1606,1494$ and 1454 $\mathrm{cm}^{-1}$ ( $v \underline{\mathrm{C}=\mathrm{C}}$ aromatic), 783 and $692 \mathrm{~cm}^{-1}\left(\delta_{\text {out of the plane }} \mathrm{C}-\mathrm{H}\right.$ of aromatic rings meta-substituted).

2-[(4-methylpiperazin-1-yl)methyl]benzenamine (5c): Yield: yellow solid (74\%); MP: $85-87{ }^{\circ} \mathrm{C} ;{ }^{1} \mathrm{H}$ NMR $\left(200 \mathrm{MHz}, \mathrm{CDCl}_{3}\right) \delta 2.21$ (s, $\left.3 \mathrm{H}, \mathrm{CH}_{3}\right), 2.37$ (ls, $8 \mathrm{H}, \mathrm{Ha}$ and $\left.\mathrm{Hb}\right), 3.44\left(\mathrm{~s}, 2 \mathrm{H}, \mathrm{CH}_{2}\right), 4.51(\mathrm{~s}, 2 \mathrm{H}$, $\left.\mathrm{NH}_{2}\right), 6.58\left(\mathrm{~m}, 2 \mathrm{H}, J=8.0 \mathrm{~Hz}, \mathrm{H} 4\right.$ ' and $\left.\mathrm{H} 5{ }^{\prime}\right), 6.89-7.05(\mathrm{~m}, 2 \mathrm{H}, \mathrm{H} 3$ ' and $\left.\mathrm{H}^{\prime}\right) ;{ }^{13} \mathrm{C}$ NMR $\left(50 \mathrm{MHz}, \mathrm{CDCl}_{3}\right) \delta 46.1(\mathrm{Cc}), 52.7$ (Ca and Ca'), 55.4 (Cb and $\left.\mathrm{Cb}^{\prime}\right), 62.0(\mathrm{Cd}), 115.6$ (C-6), 117.7 (C-4), $122.4(\mathrm{C}-2), 128.5$ (C-3), 130.6 (C-5), 147.1 (C-1); IV (KBr) $3364 \mathrm{~cm}^{-1}\left(v_{\mathrm{a}} \mathrm{NH}_{2}\right), 3303 \mathrm{~cm}^{-1}$ 
$\left(v_{\mathrm{s}} \mathrm{NH}_{2}\right), 2938$ and $2806 \mathrm{~cm}^{-1}\left(v \mathrm{CH}_{2}\right), 750 \mathrm{~cm}^{-1}\left(\delta_{\text {out of the plane }} \mathrm{C}-\mathrm{H}\right.$ of aromatic rings ortho-substituted).

2-[(4-phenylpiperazin-1-yl)methyl]benzenamine (14): Yield: white solid (84\%); MP: $178-179{ }^{\circ} \mathrm{C} ;{ }^{1} \mathrm{H}$ NMR $\left(200 \mathrm{MHz}, \mathrm{CDCl}_{3}\right) \delta$ $2.51(\mathrm{t}, 4 \mathrm{H}, J=4.9 \mathrm{~Hz}, \mathrm{Ha}), 3.09(\mathrm{t}, 4 \mathrm{H}, J=4.9 \mathrm{~Hz}, \mathrm{Hb}), 3.50(\mathrm{~s}, 2 \mathrm{H}$, $\left.\mathrm{CH}_{2}\right), 4.51\left(\mathrm{ls}, \mathrm{NH}_{2}\right), 6.54-7.21$ (9H, H-aromatics); ${ }^{13} \mathrm{C} \mathrm{NMR}(50 \mathrm{MHz}$, $\left.\mathrm{CDCl}_{3}\right) \delta 49.4\left(\mathrm{Cb}\right.$ and $\left.\mathrm{Cb}^{\prime}\right), 52.9\left(\mathrm{Ca}\right.$ and $\left.\mathrm{Ca}^{\prime}\right), 62.0(\mathrm{Cc}), 115.8(\mathrm{C}-$ 6), 116.2 (C-2' and C-6'), 117.8 (C-4), $119.9\left(\mathrm{C}^{\prime} 4^{\prime}\right), 121.9(\mathrm{C}-2), 128.8$ (C-3), 129.3 (C-3' and C-5'), 130.8 (C-5), 147.2 (C-1), 151.4 (C-1'); IV (KBr) $3443 \mathrm{~cm}^{-1}\left(v_{\mathrm{a}} \mathrm{NH}_{2}\right), 3311 \mathrm{~cm}^{-1}\left(\mathrm{v}_{\mathrm{s}} \mathrm{NH}_{2}\right), 2932$ and $2817 \mathrm{~cm}^{-1}(\mathrm{v}$ $\left.\mathrm{CH}_{2}\right), 1599,1498$ and $1451 \mathrm{~cm}^{-1}(\mathrm{v} \mathrm{C}=\mathrm{C}$ aromatic $), 746 \mathrm{~cm}^{-1}\left(\delta_{\text {out of the plane }}\right.$ $\mathrm{C}-\mathrm{H}$ of aromatic rings ortho-substituted).

2-\{[4-(pyrimidin-2-yl)piperazin-1-il]methyl\}benzenamine (15): Yield: yellow solid (81\%); MP: $100-102{ }^{\circ} \mathrm{C} ;{ }^{1} \mathrm{H}$ NMR $\left(200 \mathrm{MHz}, \mathrm{CDCl}_{3}\right)$ $\delta 2.44(\mathrm{t}, 4 \mathrm{H}, J=5.0 \mathrm{~Hz}, \mathrm{Ha}), 3.50\left(\mathrm{~s}, 2 \mathrm{H}, \mathrm{CH}_{2}\right), 3.75(\mathrm{t}, 4 \mathrm{H}, J=4.9 \mathrm{~Hz}$, $\mathrm{Hb}), 6.41\left(\mathrm{t}, 1 \mathrm{H}, J=4.7 \mathrm{~Hz}, \mathrm{H} 4{ }^{\prime \prime}\right), 6.61\left(\mathrm{t}, 2 \mathrm{H}, J=6.9 \mathrm{~Hz}, \mathrm{H} 3^{\prime}\right.$ and $\mathrm{H} 5$ '), $6.92\left(\mathrm{~d}, 1 \mathrm{H}, J=6.6 \mathrm{~Hz}, \mathrm{H} 6^{\prime}\right), 7.05$ (t, $1 \mathrm{H}, J=8.2 \mathrm{~Hz}, \mathrm{H} 4$ '), 8.22 (d, $2 \mathrm{H}$, $J=4.7 \mathrm{~Hz}, \mathrm{H} 3 "$ and $\mathrm{H} 5 ") ;{ }^{13} \mathrm{C} \mathrm{NMR}\left(50 \mathrm{MHz}, \mathrm{CDCl}_{3}\right) \delta 43.9(\mathrm{Cb}$ and Cb'), 52.8 (Ca and Ca'), 62.1 (Cc), 110.1 (C-5'), 115.9 (C-6), 117.9 (C-4), 121.7 (C-2), 128.9 (C-3), 130.9 (C-5), 147.2 (C-1), 157.9 (C-4' and C-6'), 161.8 (C-2'); IV (KBr) $3421 \mathrm{~cm}^{-1}\left(\mathrm{v}_{\mathrm{a}} \mathrm{NH}_{2}\right), 3302 \mathrm{~cm}^{-1}\left(\mathrm{v}_{\mathrm{s}} \mathrm{NH}_{2}\right), 2929$ and $2814 \mathrm{~cm}^{-1}\left(\mathrm{v} \mathrm{CH}_{2}\right), 1586,1495$ and $1448 \mathrm{~cm}^{-1}$ (v C=C aromatic), 751 $\mathrm{cm}^{-1}\left(\delta_{\text {out of the plane }} \mathrm{C}-\mathrm{H}\right.$ of aromatic rings ortho-substituted).

2-[(4-hydroxyethyl-piperazin-1-yl)methyl]benzenamine (16): Yield: yellow solid (76\%); MP: 63-65 ${ }^{\circ} \mathrm{C} ;{ }^{1} \mathrm{H} \mathrm{NMR}\left(200 \mathrm{MHz}, \mathrm{CDCl}_{3}\right) \delta$ $2.43-2.50(\mathrm{~m}, 10 \mathrm{H}, \mathrm{Ha}, \mathrm{Hb}$ and $\mathrm{Hd}), 3.44\left(\mathrm{~s}, 2 \mathrm{H}, \mathrm{CH}_{2}\right), 3.55(\mathrm{t}, 2 \mathrm{H}, J$ $=5.6 \mathrm{~Hz}, \mathrm{He}), 4.03\left(\mathrm{ls}, 2 \mathrm{H}, \mathrm{NH}_{2}\right), 6.58(\mathrm{t}, 2 \mathrm{H}, J=8.2 \mathrm{~Hz}, \mathrm{H} 4$ ' and $\mathrm{H} 5$ '), $6.93\left(\mathrm{~d}, 1 \mathrm{H}, J=7.1 \mathrm{~Hz}, \mathrm{H} 3{ }^{\prime}\right), 7.01\left(\mathrm{t}, 1 \mathrm{H}, J=7.6 \mathrm{~Hz}, \mathrm{H6}{ }^{\prime}\right) ;{ }^{13} \mathrm{C} \mathrm{NMR}$ $\left(50 \mathrm{MHz}, \mathrm{CDCl}_{3}\right) \delta 52.7\left(\mathrm{Ca}\right.$ and $\left.\mathrm{Ca}^{\prime}\right), 53.2\left(\mathrm{Cb}\right.$ and $\left.\mathrm{Cb}^{\prime}\right), 57.9(\mathrm{Cc})$, $59.5(\mathrm{Cd}), 62.0(\mathrm{Ce}), 115.6(\mathrm{C}-6), 117.7(\mathrm{C}-4), 122.2(\mathrm{C}-2), 128.5(\mathrm{C}-3)$, 130.6 (C-5), $147.0(\mathrm{C}-1)$; IV (KBr) $3373 \mathrm{~cm}^{-1}\left(v_{\mathrm{a}} \mathrm{OH}\right), 3307 \mathrm{~cm}^{-1}\left(v_{\mathrm{a}}\right.$ $\left.\mathrm{NH}_{2}\right), 3212 \mathrm{~cm}^{-1}\left(v_{\mathrm{s}} \mathrm{NH}_{2}\right), 2942$ and $2817 \mathrm{~cm}^{-1}\left(v_{\mathrm{CH}}\right), 1634,1495$ and $1456 \mathrm{~cm}^{-1}$ ( $\mathrm{C}=\mathrm{C}$ aromatic), $762 \mathrm{~cm}^{-1}$ ( $\delta_{\text {out of the plane }} \mathrm{C}-\mathrm{H}$ of aromatic rings ortho-substituted).

General procedure for preparation of the compounds $2 \mathrm{a}-\mathrm{c}$, 6-10 [12]: To a flask of the $50 \mathrm{~mL}$ containing $1 \mathrm{mmol}$ of acyl chloride derivative in dichloromethane $(20 \mathrm{~mL})$ treated with $2.2 \mathrm{mmol}$ of triethylamine was added $1 \mathrm{mmol}$ of amine-compound and the mixture stirred at room temperature for 2 hours. The mixture was diluted with additional dichloromethane $(10 \mathrm{~mL})$ and brine $(20 \mathrm{~mL})$ and washed with $0.05 \mathrm{M} \mathrm{HCl}(10 \mathrm{~mL})$ and brine $(20 \mathrm{~mL})$. The organic portion was dried $\left(\mathrm{Na}_{2} \mathrm{SO}_{4}\right)$, filtered and concentrate in vacuo.

$\mathrm{N}$-\{4-[(4-methylpiperazin-1-yl)methyl]phenyl\}quinoxaline-2carboxamide (2a; LASSBio-1599): Yield: yellow solid (64\%). When necessary, the product was purified by flash chromatography on silica gel (elution with $1 \%$ triethylamine in ethyl acetate); MP: $156^{\circ} \mathrm{C} ;{ }^{1} \mathrm{H}$ $\operatorname{NMR}\left(200 \mathrm{MHz}, \mathrm{CDCl}_{3}\right) \delta 2.26\left(\mathrm{~s}, 3 \mathrm{H}, \mathrm{CH}_{3}\right), 2.47$ (ls, $8 \mathrm{H}, \mathrm{Ha}$ and $\left.\mathrm{Hb}\right)$, $3.44\left(\mathrm{~s}, 2 \mathrm{H}, \mathrm{CH}_{2}\right), 7.19\left(\mathrm{~d}, 2 \mathrm{H}, J=8.2 \mathrm{~Hz}, \mathrm{H} 3^{\prime}\right.$ and H5'), $9.70(\mathrm{~d}, 2 \mathrm{H}, J=$ $8.2 \mathrm{~Hz}, \mathrm{H} 2$ ' and H6'), $7.77-7.82(\mathrm{~m}, 2 \mathrm{H}, \mathrm{H} 5$ and $\mathrm{H} 8), 8.07-8.15$ (m, 2H, H6 and H7), 9.67 (s, 1H, H3), 9.75 (s, 1H, CONH); ${ }^{13} \mathrm{C}$ NMR (50 $\left.\mathrm{MHz}, \mathrm{CDCl}_{3}\right) \delta 46.0(\mathrm{Cc}), 53.0\left(\mathrm{Cb}\right.$ and $\left.\mathrm{Cb}^{\prime}\right), 55.2\left(\mathrm{Ca}\right.$ and $\left.\mathrm{Ca}^{\prime}\right), \delta 62.6$ (Cd), 119.9 (C-2 and C-6), 129.7 (C-6'), 130.1 (C-3 and C-5), 131.2 (C8'), 132.0 (C-9'), 134.9 (C-7'), 136.4 (C-4), 140.2 (C-1), 143.5 (C-10'), 144.0 (C-2'), 144.2 (C-3' and C-5'), 161.0 ( $\underline{\mathrm{CONH}})$; IR (KBr) $3280 \mathrm{~cm}^{-1}$ (v CONH), 2931 and $2793 \mathrm{~cm}^{-1}\left(v \mathrm{CH}_{2}\right), 1682 \mathrm{~cm}^{-1}$ (v CONH), 830 $\mathrm{cm}^{-1}\left(\delta_{\text {out of the plane }} \mathrm{C}-\mathrm{H}\right.$ of aromatic rings para-substituted); Elementar Analysis $\mathrm{C}_{21} \mathrm{H}_{23} \mathrm{~N}_{5} \mathrm{O}$ (361): Calculated - C, 69.44; H, 6.41; N, 19.38. Found - C, 69.78; H, 6.60; N, 18.98 .
N-\{3-[(4-methylpiperazin-1-yl)methyl] phenyl\}quinoxaline-2carboxamide (2b; LASSBio-1598): Yield: yellow solid (53\%). When necessary, the product was purified by flash chromatography on silica gel (elution with $1 \%$ triethylamine in ethyl acetate); MP: $142{ }^{\circ} \mathrm{C} ;{ }^{1} \mathrm{H}$ $\operatorname{NMR}\left(200 \mathrm{MHz}, \mathrm{CDCl}_{3}\right) \delta 2.27\left(\mathrm{~s}, 3 \mathrm{H}, \mathrm{CH}_{3}\right), 2.49$ (ls, $8 \mathrm{H}, \mathrm{Ha}$ and $\left.\mathrm{Hb}\right)$, 3.49 (s, 2H, $\left.\mathrm{CH}_{2}\right), 7.07$ (d, $1 \mathrm{H}, J=7.4 \mathrm{~Hz}, \mathrm{H} 4$ '), $7.30(\mathrm{t}, 1 \mathrm{H}, J=7.7 \mathrm{~Hz}$, H5'), 7.65 (s, 1H, H6'), 7.74 (s, 1H, H2'), $7.79-7.84$ (m, 2H, H6 and H7), $8.09-8.16$ (m, 2H, H5 and H8), 9.69 (s, 1H, H3), 9.79 (s, 1H, $\mathrm{CONH}) ;{ }^{13} \mathrm{C}$ NMR $\left(50 \mathrm{MHz}, \mathrm{CDCl}_{3}\right) \delta 45.8(\mathrm{Cc}), 52.8\left(\mathrm{Cb}\right.$ and $\left.\mathrm{Cb}^{\prime}\right)$, $55.0\left(\mathrm{Ca}\right.$ and $\left.\mathrm{Ca}^{\prime}\right), 62.8(\mathrm{Cd}), 118.8$ - 144.1 (14C, C-aromatic), 161.0 (CONH); IV ( $\mathrm{KBr}) 3257 \mathrm{~cm}^{-1}$ (v CONH), 2945 and $2794 \mathrm{~cm}^{-1}\left(v \mathrm{CH}_{2}\right)$, $1680 \mathrm{~cm}^{-1}$ (v CONH) 1607, 1537 and $1488 \mathrm{~cm}^{-1}$ (v C=C aromatic); Elementar Analysis $\mathrm{C}_{21} \mathrm{H}_{23} \mathrm{~N}_{5} \mathrm{O}$ (361): Calculated - C, 69.44; $\mathrm{H}, 6.41 ; \mathrm{N}$, 19.38. Found - C, 69.32; H, 6.18; N, 19.38 .

$\mathrm{N}-\{2-[(4-m e t h y l p i p e r a z i n-1-y l)$ methyl $]$ phenyl $\}$ quinoxaline-2carboxamide (2c; LASSBio-1597): Yield: yellow solid (51\%). When necessary, the product was purified by flash chromatography on silica gel (elution with $1 \%$ triethylamine in ethyl acetate); MP: $132{ }^{\circ} \mathrm{C} ;{ }^{1} \mathrm{H}$ NMR $\left(200 \mathrm{MHz}, \mathrm{CDCl}_{3}\right) \delta 2.30\left(\mathrm{~s}, 3 \mathrm{H}, \mathrm{CH}_{3}\right), 2.64(\mathrm{ls}, 8 \mathrm{H}, \mathrm{Ha}$ and $\mathrm{Hb}), 3.64\left(\mathrm{~s}, 2 \mathrm{H}, \mathrm{CH}_{2}\right), 6.99-8.43(\mathrm{~m}, 8 \mathrm{H}, \mathrm{H}$-aromatics), $9.69(\mathrm{~s}, 1 \mathrm{H}$, H3'), 11.70 (s, 1H, CONH); ${ }^{13} \mathrm{C}$ NMR (50 MHz, $\mathrm{CDCl}_{3}$ ) $\delta 45.7$ (Cc), $52.3\left(\mathrm{Cb}\right.$ and $\left.\mathrm{Cb}^{\prime}\right), 55.1$ (Ca and $\left.\mathrm{Ca}^{\prime}\right), 61.5(\mathrm{Cd}), 121.9-145.03(14 \mathrm{C}$ C-aromatics), $162.0(\mathrm{CONH})$; IR (KBr) $3238 \mathrm{~cm}^{-1}$ (v CONH), 2933 and $2795 \mathrm{~cm}^{-1}\left(v \mathrm{CH}_{2}\right), 1684 \mathrm{~cm}^{-1}(v \mathrm{CONH}) 1590,1525$ and 1450 $\mathrm{cm}^{-1}$ (v C=C aromatic), $753 \mathrm{~cm}^{-1}\left(\delta_{\text {out of the plane }} \mathrm{C}-\mathrm{H}\right.$ of aromatic rings ortho-substituted); Elementar Analysis $\mathrm{C}_{21} \mathrm{H}_{23} \mathrm{~N}_{5} \mathrm{O}$ (361): Calculated C, 69.78; H, 6.41; N, 19.38. Found: C, 69.44; H, 5.99; N, 19.21; HPLC (C-18, acetonitrile: aqueous trifluoroacetic acid (30:70), $254 \mathrm{~nm}$ ): Retention time: 7.64 min. Peak Area: $98.928 \%$.

N-\{2-[(4-methylpiperazin-1-yl)methyl]phenyl $\}$ pyrazine-2carboxamide (6; LASSBio-1724): Yield: yellow solid (72\%). When necessary, the product was purified by flash chromatography on silica gel (elution with $1 \%$ triethylamine in ethyl acetate); MP: $134{ }^{\circ} \mathrm{C} ;{ }^{1} \mathrm{H}$ $\operatorname{NMR}\left(200 \mathrm{MHz}, \mathrm{CDCl}_{3}\right) \delta 2.35\left(\mathrm{~s}, 3 \mathrm{H}, \mathrm{CH}_{3}\right), 2.62(\mathrm{ls}, 8 \mathrm{H}, \mathrm{Ha}$ and $\mathrm{Hb})$, $3.59\left(\mathrm{~s}, 2 \mathrm{H}, \mathrm{CH}_{2}\right), 6.98-7.13\left(\mathrm{~m}, 2 \mathrm{H}, \mathrm{H} 3^{\prime}\right.$ and $\left.\mathrm{H} 4{ }^{\prime}\right), 7.30(\mathrm{t}, 1 \mathrm{H}, J=7.0$ $\mathrm{Hz}, \mathrm{H} 5), 8.37$ (d, $1 \mathrm{H}, J=8.0 \mathrm{~Hz}, \mathrm{H} 6$ ) $), 8.52$ (s, 1H, H6), 8.72 (d, 1H, $J$ $=2.3 \mathrm{~Hz}, \mathrm{H} 5), 9.45(\mathrm{~s}, 1 \mathrm{H}, \mathrm{H} 3), 12.12(\mathrm{~s}, 1 \mathrm{H}, \mathrm{CONH}) ;{ }^{13} \mathrm{C} \mathrm{NMR}(50$ $\left.\mathrm{MHz}, \mathrm{CDCl}_{3}\right) \delta 45.7(\mathrm{Cc}), 52.1\left(\mathrm{Cb}\right.$ and $\left.\mathrm{Cb}^{\prime}\right), 54.8\left(\mathrm{Ca}\right.$ and $\left.\mathrm{Ca}^{\prime}\right), 61.6$ (Cd), 121.5 (C-6), 124.2 (C-4), 126.8 (C-5), 128.7 (C-3), 130.2 (C-2), 137.9 (C-1), 142.5 (C-3'), 145.2 (C-5'), 145.8 (C-2'), 147.2 (C-6'), 161.5 (CONH); IR (KBr) $3456 \mathrm{~cm}^{-1}$ (v CONH), 2937 and $2795 \mathrm{~cm}^{-1}\left(\mathrm{v} \mathrm{CH}_{2}\right)$, $1677 \mathrm{~cm}^{-1}$ (v CONH) 1590, 1534 and $1452 \mathrm{~cm}^{-1}$ (v C=C aromatic), $756 \mathrm{~cm}^{-1}$ ( $\delta_{\text {out of the plane }} \mathrm{C}-\mathrm{H}$ of aromatic rings ortho-substituted); HPLC (C-18, acetonitrile: aqueous trifluoroacetic acid (30:70), $254 \mathrm{~nm}$ ): Retention time: 3.136 min. Peak Area: $95.355 \%$.

$N$-\{2-[(4-methylpiperazin-1-yl)methyl]phenyl\}quinoxaline-6carboxamide (7; LASSBio-1725): Yield: yellow solid (64\%). When necessary, the product was purified by flash chromatography on silica gel (elution with $1 \%$ triethylamine in ethyl acetate); MP: $128{ }^{\circ} \mathrm{C} ;{ }^{1} \mathrm{H}$ $\operatorname{NMR}\left(200 \mathrm{MHz}, \mathrm{CDCl}_{3}\right) \delta 2.31\left(\mathrm{~s}, 3 \mathrm{H}, \mathrm{CH}_{3}\right), 2.59$ (sl, $8 \mathrm{H}, \mathrm{Ha}$ and $\left.\mathrm{Hb}\right)$, $3.66\left(\mathrm{~s}, 2 \mathrm{H}, \mathrm{CH}_{2}\right), 6.97-7.13\left(\mathrm{~m}, 2 \mathrm{H}, \mathrm{H} 3{ }^{\prime}\right.$ and $\left.\mathrm{H} 4{ }^{\prime}\right), 7.31(\mathrm{t}, 1 \mathrm{H}, J=8.3$ $\mathrm{Hz}, \mathrm{H} 5$ '), $8.16\left(\mathrm{~d}, 1 \mathrm{H}, J=8.7 \mathrm{~Hz}, \mathrm{H} 6^{\prime}\right), 8.31-8.42(\mathrm{~m}, 2 \mathrm{H}, \mathrm{H} 4$ and $\mathrm{H} 5)$, 8.62 (s, 1H, H7), 8.86 (s, 2H, H9 and $\mathrm{H} 10), 11.61$ (s, $1 \mathrm{H}, \mathrm{CONH}) ;{ }^{13} \mathrm{C}$ NMR (50 MHz, $\mathrm{CDCl}_{3}$ ) $\delta 45.6$ (Cc), 52.5 (Cb e Cb'), 54.7 (Ca e Ca'), $62.4(\mathrm{Cd}), 121.0$ - 146.4 (14C, C-aromáticos), 164.2 (CONH); IR (KBr) $3467 \mathrm{~cm}^{-1}$ (v CONH), 2937 e $2809 \mathrm{~cm}^{-1}\left(v \mathrm{CH}_{2}\right), 1672 \mathrm{~cm}^{-1}$ (v CONH) 1591,1529 e $1448 \mathrm{~cm}^{-1}$ (v C=C aromático), $749 \mathrm{~cm}^{-1}$ ( $\delta_{\text {out of the plane }} \mathrm{C}-\mathrm{H}$ aromatic rings ortho-substituted); HPLC (C-18, acetonitrile: aqueous trifluoroacetic acid (30:70), $254 \mathrm{~nm}$ ): Retention time: 3.688 min. Peak Area: $95.913 \%$. 
$\mathrm{N}$-\{2-[(4-phenylpiperazin-1-yl)methyl]phenyl\}quinoxaline-2carboxamide (8; LASSBio-1726): Yield: yellow solid (59\%). When necessary, the product was purified by flash chromatography on silica gel (elution with $20 \%$ ethyl acetate in $n$-hexane); MP: $179{ }^{\circ} \mathrm{C} ;{ }^{1} \mathrm{H}$ NMR $\left(200 \mathrm{MHz}, \mathrm{CDCl}_{3}\right) \delta 2.69(\mathrm{t}, 4 \mathrm{H}, J=4.5 \mathrm{~Hz}, \mathrm{Ha}), 3.29(\mathrm{t}, 4 \mathrm{H}, J=4.7 \mathrm{~Hz}$, $\mathrm{Hb}), 3.67\left(\mathrm{~s}, 2 \mathrm{H}, \mathrm{CH}_{2}\right), 6.74-8.42(13 \mathrm{H}, \mathrm{H}$-aromatics), $9.66(\mathrm{~s}, 1 \mathrm{H}, \mathrm{H} 3)$, $11.90(\mathrm{~s}, 1 \mathrm{H}, \mathrm{CONH}) ;{ }^{13} \mathrm{C} \mathrm{NMR}\left(50 \mathrm{MHz}, \mathrm{CDCl}_{3}\right) \delta 49.4\left(\mathrm{Cb}\right.$ and $\left.\mathrm{Cb}^{\prime}\right)$, 53.0 (Ca and $\left.\mathrm{Ca}^{\prime}\right), 62.0(\mathrm{Cc}), 116.3-151.3$ (20C, C-aromatics), 162.3 ( $\underline{\mathrm{CONH}})$; IR $(\mathrm{KBr}) 3217 \mathrm{~cm}^{-1}(\mathrm{v} \mathrm{CONH}), 2938$ and $2825 \mathrm{~cm}^{-1}\left(\mathrm{v} \mathrm{CH}_{2}\right)$, $1679 \mathrm{~cm}^{-1}$ (v CONH) 1591, 1527 and $1452 \mathrm{~cm}^{-1}$ (v C=C aromatic), 754 $\mathrm{cm}^{-1}\left(\delta_{\text {out of the plane }} \mathrm{C}-\mathrm{H}\right.$ of aromatic rings ortho-substituted); $\operatorname{HPLC}(\mathrm{C}-18$, acetonitrile: aqueous trifluoroacetic acid (50:50), $254 \mathrm{~nm}$ ): Retention time: 5.055 min. Peak Area: $97.413 \%$.

$\mathrm{N}$-\{2-[(4-(pyrimidin-2-yl)piperazin-1-yl)methyl]phenyl $\}$ quinoxaline-2-carboxamide (9; LASSBio-1723): Yield: yellow solid (58\%). When necessary, the product was purified by flash chromatography on silica gel (elution with $30 \%$ ethyl acetate in $n$-hexane); MP: $216^{\circ} \mathrm{C} ;{ }^{1} \mathrm{H}$ NMR $\left(200 \mathrm{MHz}, \mathrm{CDCl}_{3}\right) \delta 2.60(\mathrm{ls}, 4 \mathrm{H}, \mathrm{Ha})$, $3.66\left(\mathrm{~s}, 2 \mathrm{H}, \mathrm{CH}_{2}\right), 3.92$ (ls, $\left.4 \mathrm{H}, \mathrm{Hb}\right), 6.39-8.47$ (11H, H-aromatics), $9.72(\mathrm{~s}, 1 \mathrm{H}, \mathrm{H} 3), 11.91(\mathrm{~s}, 1 \mathrm{H}, \mathrm{CON} \underline{\mathrm{H}}) ;{ }^{3} \mathrm{C} \mathrm{NMR}\left(50 \mathrm{MHz}, \mathrm{CDCl}_{3}\right) \delta$ 44.0 ( $\mathrm{Cb}$ and $\left.\mathrm{Cb}^{\prime}\right), 52.8$ (Ca and $\left.\mathrm{Ca}^{\prime}\right), 62.0(\mathrm{Cc}), 110.1-161.7$ (18C, C-aromatics), 162.2 ( $\underline{\mathrm{CONH}}) ; \mathrm{IV}(\mathrm{KBr}) 3221 \mathrm{~cm}^{-1}$ (v CONH), 2930 and $2817 \mathrm{~cm}^{-1}\left(v \mathrm{CH}_{2}\right), 1681 \mathrm{~cm}^{-1}(v \mathrm{CONH}) 1585,1539$ and $1447 \mathrm{~cm}^{-1}$ (v $\mathrm{C}=\mathrm{C}$ aromatic), $753 \mathrm{~cm}^{-1}\left(\delta_{\text {out of the plane }} \mathrm{C}-\mathrm{H}\right.$ of aromatic rings orthosubstituted); HPLC (C-18, acetonitrile: aqueous trifluoroacetic acid (50:50), $254 \mathrm{~nm}$ ): Retention time: 3.300 min. Peak Area: $98.053 \%$.

$\mathrm{N}$-\{2-[(4-(2-hydroxyethyl)piperazin-1-yl)methyl]phenyl $\}$ quinoxaline-2-carboxamide (10; LASSBio-1727): Yield: yellow solid (62\%). When necessary, the product was purified by flash chromatography on silica gel (elution with ethyl acetate); MP: $150{ }^{\circ} \mathrm{C}$; ${ }^{1} \mathrm{H}$ NMR (200 MHz, CDCl $) \delta 2.65$ (ls, 8H, Ha and $\left.\mathrm{Hb}\right), 3.11(\mathrm{ls}, 2 \mathrm{H}$, $\mathrm{Hc}), 3.59(\mathrm{t}, 3 \mathrm{H}, J=5.0 \mathrm{~Hz}, \mathrm{He}$ and $\mathrm{Hf}), 3.64\left(\mathrm{~s}, 2 \mathrm{H}, \mathrm{CH}_{2}\right), 7.00-8.44$ (8H, H-aromatics), 9.70 (s, 1H, H3), 11.75 (s, 1H, CONH); ${ }^{13} \mathrm{C}$ NMR $\left(50 \mathrm{MHz}, \mathrm{CDCl}_{3}\right) \delta 52.7$ (Ca and $\left.\mathrm{Ca}^{\prime}\right), 53.1$ (Cb and $\left.\mathrm{Cb}^{\prime}\right), 57.8(\mathrm{Cd}), 59.4$ (Cc), 61.6 (Ce), 121.9 - 145.0 (14C, C-aromatics), 162.0 (CONH); IR (KBr) $3390 \mathrm{~cm}^{-1}(v \mathrm{OH}), 3213 \mathrm{~cm}^{-1}(v \mathrm{CONH}), 2934$ and $2812 \mathrm{~cm}^{-1}$ (v $\left.\mathrm{CH}_{2}\right), 1680 \mathrm{~cm}^{-1}$ (v CONH) 1591, 1538 and $1452 \mathrm{~cm}^{-1}$ (v C=C aromatic), $755 \mathrm{~cm}^{-1}$ ( $\delta_{\text {out of the plane }} \mathrm{C}-\mathrm{H}$ of aromatic rings ortho-substituted); HPLC (C-18, acetonitrile: aqueous trifluoroacetic acid (50:50), $254 \mathrm{~nm}$ ): Retention time: 6.463 min. Peak Area: 98.748 \%.

\section{X-ray crystallography}

Single crystals of the compounds 2a-c (Table 4), suitable for X-ray study, were obtained by slow evaporation of a solution of ethanol-dimethylformamide (3:1), ethanol-dimethyl sulfoxidedichloromethane (1:1:1) and methanol:dichloromethane (10:1), respectively, at room temperature 295(2) K. Data collection was performed using the Kappa Apex II Duo diffractometer operating with Mo-Ka radiation $(\lambda=0.71073 \AA)$ an room temperature. Raw data integration was performed with Saint (Bruker, 2009) and the scaling were carried out using SADABS (Bruker, 2009). Structure solution was obtained using Direct Methods implemented in SHELXS and the model refinement was performed with full matrix least squares on $\mathrm{F}^{2}$ using SHELXL. The programs ORTEP-3, [13] SHELXS/SHELXL [18] were used within WinGX [19] software package.

\begin{tabular}{|c|c|c|c|}
\hline Compound & $2 a$ & 2b & 2c \\
\hline Crystal system & Monoclinic & Monoclinic & Monoclinic \\
\hline Space group & $\mathrm{P} 2 / \mathrm{c}$ & $\mathrm{P} 2 / \mathrm{c}$ & $\mathrm{P} 2 / \mathrm{c}$ \\
\hline \multicolumn{4}{|c|}{ Unit cell dimensions } \\
\hline$a(\AA)$ & $17.651(4)$ & $6.3082(3)$ & $5.7947(12)$ \\
\hline$b(\AA)$ & $5.8253(14)$ & $26.4257(14)$ & $16.576(4)$ \\
\hline$c(\AA)$ & $19.925(4)$ & $11.5607(6)$ & $20.465(4)$ \\
\hline$\beta\left({ }^{\circ}\right)$ & $108.344(7)$ & $98.802(3)$ & $106.312(11)$ \\
\hline Volume $\left(\AA^{3}\right)$ & $1944.6(7)$ & $1904.46(17)$ & $1886.7(7)$ \\
\hline Z & 4 & 4 & 4 \\
\hline Density Calculated $\left(\mathrm{Mg} / \mathrm{m}^{3}\right)$ & 1.235 & 1.261 & 1.272 \\
\hline Absorption coefficient $\left(\mathrm{mm}^{-1}\right)$ & 0.079 & 0.081 & 0.082 \\
\hline$F(000)$ & 768 & 768 & 768 \\
\hline Crystal size $\left(\mathrm{mm}^{3}\right)$ & $0.25 \times 0.2 \times 0.2$ & $0.32 \times 0.19 \times 0.04$ & $0.41 \times 0.14 \times 0.07$ \\
\hline$\theta$ range $\left({ }^{\circ}\right)$ & 2.11 to 26.23 & 1.54 to 25.39 & 1.61 to 26.47 \\
\hline \multicolumn{4}{|c|}{ Index ranges } \\
\hline $\mathrm{h}$ & -21 to 21 & -7 to 7 & -7 to 7 \\
\hline $\mathrm{k}$ & -7 to 7 & -30 to 31 & -19 to 20 \\
\hline 1 & -24 to 15 & -13 to 13 & -25 to 23 \\
\hline Reflections collected & 14313 & 9930 & 14347 \\
\hline Independent reflections & 3881 & 3410 & 3858 \\
\hline $\mathrm{R}$ (int) & 0.0459 & 0.0500 & 0.0223 \\
\hline Completeness to $\theta=25^{\circ}(\%)$ & 99.1 & 99.3 & 99.2 \\
\hline Data / restraints / parameters & $3881 / 0 / 245$ & 3410 / 0 / 244 & 3858 / 0 / 246 \\
\hline Goodness-of-fit on $\mathrm{F}^{2}$ & 1.064 & 1.021 & 1.044 \\
\hline Final R1 indices [I>2 $\sigma(I)]$ & 0.0410 & 0.0542 & 0.0399 \\
\hline Final wR2 indices $[\mid>2 \sigma(I)]$ & 0.1276 & 0.1325 & 0.1059 \\
\hline $\mathrm{R}$ indices (all data) & 0.0577 & 0.0908 & 0.0544 \\
\hline $\mathrm{R}$ indices (all data) & 0.1442 & 0.1532 & 0.1146 \\
\hline Extinction coefficient & $0.0113(19)$ & & $0.0083(12)$ \\
\hline Largest diff. peak / hole $\left(\mathrm{e} . \AA^{-3}\right)$ & $0.214 /-0.174$ & $0.156 /-0.167$ & $0.168 /-0.152$ \\
\hline
\end{tabular}

Table 4: Crystal data and structure refinement details of compounds 2a-c. 


\section{Biological assays}

All experiments were performed with male Swiss mice $(20-25 \mathrm{~g})$ obtained from Instituto Vital Brazil (Niterói, Brazil). Animals were maintained in temperature-controlled room $\left(22 \pm 2^{\circ} \mathrm{C}\right)$ with a 12 $\mathrm{h}$ light/dark cycles and free access to food and water. Twelve hours prior to each experiment, the animals received only water in order to avoid food interfering with the substance absorption. Animal care and research protocols (DFBCICB015-04/16) were in accordance with the principles and guidelines adopted by the National Council of Control of Animal Experimentation (CONCEA).

MTT assay [14]: The tumor cells used HL-60 (human leukemia ATCC code: CCL-240 ${ }^{\mathrm{TM}}$ ), HCT-8 (human colorectal carcinoma - ATCC code: CCL-244 ${ }^{\mathrm{TM}}$ ) and SF-295 (human glioblastoma) were provided by the National Cancer Institute (USA). Human lymphocytes were isolated from heparinized blood from healthy, non-smoker donors who had not taken any medication at least 15 days prior to sampling by a standard method of density-gradient centrifugation on Histopaque-1077 (Sigma Aldrich Co. - St. Louis, MO/USA). Cancer cells and lymphocytes were incubated in RPMI 1640 supplemented with $10 \%$ (tumor cells) or $20 \%$ (lymphocytes) fetal calf serum. Lymphocytes cultures were also supplemented with $2 \%$ phytohaemagglutinin. Cells were seeded in 96 well plates at the following densities: $0.3 \times 10^{6}(\mathrm{HL}-60), 0.7 \times 10^{5}$ (HCT8, SF-295), and $1 \times 10^{6}$ (lymphocytes) cells $/ \mathrm{mL}$. After 24 hour, the compounds were added at concentrations ranging from $0.1 \mu \mathrm{M}-300$ $\mu \mathrm{M}$ and then incubated at $37^{\circ} \mathrm{C}$ and atmosphere containing $5 \% \mathrm{CO}_{2}$ for 72 hours. After that, it was added $100 \mu \mathrm{L}$ of a solution of MTT $(5 \mathrm{mg} /$ $\mathrm{mL}$ ) in RPMI medium and incubated for 3 hour at the same conditions. After incubation time, it was added $100 \mu \mathrm{L}$ of DMSO for solubilization of MTT-formazan crystals formed by the metabolism of MTT salt by the viable cells. Finally, the plates were read on an ELISA reader at a wavelength of $550 \mathrm{~nm}$.

The experiments were analyzed according to their means and standard error media (S.E.M.) confidence intervals from nonlinear regression in GraphPad Prism. Each sample was tested in triplicate in two independent experiments.

Air pouch synovial model [15]: The method was similar to that described by Romano et al. [16] with several modifications described in Raymundo et al. [17]. Briefly, air pouches were produced by subcutaneous injection of sterile air $(10 \mathrm{ml})$ into the intrascapular region of the mice. After three days, another injection of air $(10 \mathrm{ml})$ was performed in order to maintain the pouches. Three days after the last injection of air, animals received an injection of sterile carrageenan suspension (1\%) into the SAP. Mice were pre-treated with oral doses of substances, ASA or vehicle $1 \mathrm{~h}$ before carrageenan injection in the SAP. Animals were sacrificed $24 \mathrm{~h}$ after carrageenan injection and the cavity was washed with $1 \mathrm{ml}$ of sterile PBS. The total number of cells was determined with the aid of a haemocytometer (CellPoucH, Merck, USA). The exudates were centrifuged at $170 \mathrm{xg}$ for $10 \mathrm{~min}$ at $4^{\circ} \mathrm{C}$, and the supernatants were collected and stored at $-20^{\circ} \mathrm{C}$ to further analysis. Supernatants from exudates collected in the SAP were used to measure tumor necrosis factor- $\alpha$ (TNF- $\alpha$ ) by enzyme-linked immunosorbent assay (ELISA), using the protocol supplied by the manufacturer (B\&D, USA).

\section{Statistical analysis}

The results are presented as mean \pm standard deviation (SD), mean \pm error deviation or mean \pm confidence interval using the GraphPad Prism vs. 5.0. Statistical significance between groups was calculated using analysis of variance (ANOVA) followed by Bonferroni or Dunnet tests. $\mathrm{P}$ values less than $0.05\left({ }^{*} \mathrm{p}<0.05\right)$ were used as significant level.

\section{Acknowledgments}

The authors would like to thank INCT-INOFAR (573.564/2008-6 and E-26/170.020/2008), CNPq (BR), FAPERJ (BR) and CAPES (BR) for fellowship and financial support. We also thank Dr. Nailton Monteiro do Nascimento Júnior for his valuable help with the NMR spectra analysis.

\section{References}

1. Capdeville R, Buchdunger E, Zimmermann J, Matter A (2002) Glivec (STI57, imatinib), a rationally developed, targeted anticancer drug. Nat Rev Drug Discov 1: 493-502.

2. Lydon NB, Druker BJ (2004) Leukemia Res 28S: 29-38.

3. Akhmetshina A, Venalis P, Dees C, Busch N, Zwerina J, et al. (2009) Treatment with imatinib prevents fibrosis in different preclinical models of systemic sclerosis and induces regression of established fibrosis. Arthritis \& Rheumatism 60: 219-224.

4. Kim I, Rhee C, Yeo C, Kang H, Lee D, et al. (2013) 17: R114.

5. Huang $P$, Zhao XS, Fields M, Ransohoff RM, Zhou L (2009) Imatinib attenuates skeletal muscle dystrophy in mdx mice. FASEB J 23: 2539-2548.

6. Wolf AM, Wolf D, Rumpold H, Ludwiczek S, Enrich B, et al. (2005) The kinase inhibitor imatinib mesylate inhibits TNF-\{alpha\} production in vitro and prevents TNF-dependent acute hepatic inflammation. Proc Natl Acad Sci U S A 102: 13622-13627.

7. Miyachi K, Ihara A, Hankins RW, Murai R, Maehiro S, et al. (2003) Efficacy of imatinib mesylate (STI571) treatment for a patient with rheumatoid arthritis developing chronic myelogenous leukemia. Clin Rheumatol 22: 329-332.

8. Barreiro EJ (2002) Estratégia De Simplificação Molecular No Planejamento Racional De Fármacos: A Descoberta De Novo Agente Cardioativ. Quimica Nova 25: 1172-1180.

9. Lima LM, Barreiro EJ (2005) Bioisosterism: a useful strategy for molecular modification and drug design. Curr Med Chem 12: 23-49.

10. Kim S, Oh CH, Ko JS, Ahn KH, Kim YJ (1985) Zinc-modified cyanoborohydride as a selective reducing agent. J Org Chem 50: 1927-1932.

11. Li CS, Black WC, Chan CC, Ford-Hutchinson AW, Gauthier JY, et al. (1995) Cyclooxygenase-2 Inhibitors. Synthesis and Pharmacological Activities of 5-Methanesulfonamido-1-indanone Derivatives. J Med Chem 38: 4897-4905.

12. Kort ME, Drizin I, Gregg RJ, Scanio MJC, Shi L, et al. (2008) Discovery and Biological Evaluation of 5-Aryl-2-furfuramides, Potent and Selective Blockers of the $\mathrm{Na}_{\mathrm{v}} 1.8$ Sodium Channel with Efficacy in Models of Neuropathic and Inflammatory Pain. J Med Chem 5: 407-416.

13. Farrugia LJ (1997) ORTEP-3 for Windows - a version of ORTEP-III with a Graphical User Interface (GUI). J Appl Cryst 30: 565.

14. Mosmann T (1983) Rapid colorimetric assay for cellular growth and survival application to proliferation and cytotoxicity assays. J Immunol Methods 65: 55-63.

15. Edwards JC, Sedgwick AD, Willoughby DA (1981) The formation of a structure with the features of synovial lining by subcutaneous injection of air: an in vivo tissue culture system. J Pathol 134: 147-156.

16. Romano M, Faggioni R, Sironi M, Sacco S, Echtenacher B, et al. (1997) Carrageenan-induced acute inflammation in the mouse air pouch synovial model. Role of tumour necrosis factor. Mediators Inflamm 6: 32-38.

17. Raymundo LJ, Guilhon CC, Alviano DS, Matheus ME, Antoniolli AR, et al. (2011) Characterisation of the anti-inflammatory and antinociceptive activities of the Hyptis pectinata (L.) Poit essential oil. J Ethnopharmacol 134: 725-732.

18. Sheldrick GM (2008) A short history of SHELX. Acta Crystallogr A 64: 112-122.

19. Farrugia LJ (1999) WinGX suite for small-molecule single-crystal crystallography. J Appl Crystallogr 32: 837-828. 